\title{
VIEJOS Y NUEVOS PARADIGMAS EN LA ENSEÑANZA DE LA BIOLOGIA
}

Giovanni Aragón Alvarado ${ }^{1}$

\section{INTRODUCCION}

Es muy difícil alcanzar puntos de encuentro entre los profesionales que ejercen una cienciao actividad, especialmente si de lo que se trata es plantear un sistema referencial para lograr el desarrollo de la misma, a partir de su relación con la realidad. Como dice Von Uexküll: “...el universo sensible es totalmente distinto, según se trate de una hormiga, de una rana, de un bebé, de un aborigen australiano, de un ateniense, de un monje medieval o de un neoyorquino de nuestros días ...". Por las características tan diversas y ambiguas del concepto de realidad es que cada uno de nosotros percibimos las cosas de diferente manera. Por ello existe diversidad de opiniones para dar un tratamiento adecuado a los contenidos de los cursos a dictarse en una determinada cátedra.

En el presente ensayo, se trata este problema, primero desde el punto de vista de la concepción anterior y actual de la ciencia y la actividad del hombre en la búsqueda del conocimiento. Luego se propone las características de la biología como ciencia y los cambios que ha sufrido a través de la historia como una manera de concebir su estructura curricular. Y, finalmente, los aspectos filosóficos a considerar en la elaboración de un currículo de Biología, partiendo de un análisis de la realidad.

\section{LA CIENCIA Y EL HOMBRE EN LA ACTUALIDAD}

Las reflexiones que hace Pedro Makabe en su obra El Cambio Epistemológico, respecto a los cambios que ocurren en el mundo actual de la ciencia, nos motiva a cuestionar muchos de los aspectos relacionados a la práctica docente en cuanto a: metodología, estructura, función, actores y contenidos curriculares, cuando señala que: “...los grandes problemas de nuestro tiempo son facetas de unaúnica crisis, que es la crisis de percepción Intentamos aplicar los conceptos obsoletos de una reduccionista visión del mundo-laperspectiva mecanicista de la ciencia-a una realidad que no puede ser comprendida en esos términos...". Si se tiene en cuenta que el mundo

\section{Biólogo}

en que vivimos está globalmente interconectado por los fenómenos biológicos, psicológicos, sociales y ambientales, $y$ todos ellos interdependientes, entonces será necesaria una nueva forma de ver la realidad, estableciendo nuevos parámetros para su concepción y una nueva escala de valores. "...Los comienzos de este cambio son ya visibles en todas las áreas; y la mutación de una concepción mecanicista a una concepción integradora de la realidad será probablemente lo que caracterizará al futuro cercano..." (Makabe, p. 79). El hombremodernoenlabúsqueda de launidad fundamental de la materia -al comienzo la molécula, luego el átomo, seguidamente el núcleo atómico, etc.- ha concluido en que esta búsqueda ha sido infructuosa. "...Nuestro mundo es diferente a todo lo imaginado, no tiene solidez. Mas, en el nuevo paradigma, la materia, el tiempo y el espacio desaparecen como absolutos. Sólo existen oscilaciones. Ha desaparecido la consistencia absoluta de nuestro mundo. El viejo paradigma ya no es adecuado..." (Makabe, pg. 80). Para comprender mejor esta proposición es conveniente conocer los alcances de la mecánica newtoniana y los aportes de la termodinámica en la apreciación de la realidad. Así "...la mecánica newtoniana es válida para un cierto campo, para cuerpos que se mueven en campos cuyas fuerzas son perfectamente conocidas. Pero siuno va aumentando la complejidad del sistema, hacia el nivel químico o biológico, hastallegar a la sociología o ecología,... nos encontramos con fenómenos en los que el azar y el determinismo se combinan de una forma u otra..." (Makabe pg. 81).

La ciencia occidental ha mantenido durante muchotiempo una visión mecanicista (el "adormecimiento newtoniano" como lo llamó William Blake). “...La ciencia está redescubriendo la importancia de la secuencia temporal de los fenómenos. Esta es la revolución conceptual descrita por el Nobel de Química 1977, el belga llya Prigogine. Es la nueva ciencia de la complejidad, que involucra la interacción entre un gran número de elementos..." (Makabe, pg. 83). Esta nueva concepción de la ciencia permite reconocer que la realidad, tal como se conoció hasta hace algún tiempo atrás, ha dejado de existir en un sentido fundamental. Esta nueva realidad está constituida de interconexiones y de relaciones que emparentan a todas las entidades, ya sean animadas o 
inanimadas. Las investigaciones de las funciones humanas conducen a la conclusión de que la mente es una entidad mucho más vasta que el cerebro y que nuestro intelecto no-consciente es capaz de proezas increibles. Si se potencializa al individuo, otorgándosele libertad para la elección autónoma, el resultado será un mayor aprendizaje, una mayor creatividad que las logradas mediante elejercicio del poder sobre la persona. De esta manera, el hombre no puede seguir siendo considerado como una gran computadora, un manojo mecánico de estímulos y respuestas. Nuestra concepción de la persona se enfrenta a cambios drásticos. Tal persona posee capacidades inimaginadas hasta ahora. Todo indica que debemos percibir al individuo como un ser en constante transformación, una persona trascendente.

\section{LABIOLOGIA COMO CIENCIA}

Cuando se termina de enseñar un curso, puede ocurrir que los profesores nos preguntemos, entre otras cosas, si nuestros alumnos han aprendido realmente lo que deben o necesitan aprender y en qué medida les va a servir lo que se les ha enseñado. Aparte de lo que pueden significar los recursos didácticos empleados, hay otros factores educacionales de los currículos que deben considerarse cuando se quiere hacer un análisis de nuestra situación educacional. La biología como ciencia, también es "...un sistema de conocimiento del hombre sobre la naturaleza, la sociedad y el pensamiento. Refleja el mundo en conceptos, categorías y leyes cuya veracidad se comprueba porla práctica..." (Afanasiev p. 358).

Alenseñarbiología, ¿pretendemos que nuestros alumnos alcancen ese sistema de conocimiento?, o nos limitamos a una parte de él simplemente. Entonces cabe recordar a Jacob Bronowski, cuando dicen: Uno de los propósitos de las ciencias físicas hasido el de proporcionar una imagen exacta del mundo material. Uno de los logros de la física del siglo $X X$ ha sido el de probar que tal meta es inasequible. La física ha demostrado que no existe el conocimiento absoluto. $Y$ aquellos que lo sostienen; trátese de científicos o dogmáticos, abren la puerta a la tragedia. Toda información es imperfecta; tenemos que manejarla con humildad. Tal es la condición humana; y asi lo expresa la física cuántica" (Makabep.62). Lafísica cuántica permitió superar el determinismo de la física mecánica y es así que Popper (1934), respecto al principio oley, señala que es: “...un enunciado imperfecto o provisional que algún día será sustituido por otra ley superior, de la cual la primera no es sino una imagen grosera..." Esto se ha comprobado históricamente, es así que conceptos y teorías que parecían irrefutables, resultaron superadas o englobadas por otras más generales, reconociendo que tales son sólo postulados temporales y circunstanciales. La biología como ciencia también está sujeta a las mismas características, ya que históricamente ha sufrido los cambios conceptuales que afirma la física cuántica y tenemos que asumir que efectivamente, toda información es imperfecta y hay que manejarla con humildad. La biología ha sufrido cambios drásticos, de una biología clásica, descriptiva, estática, biométrica, a una biología moderna, dinámica, experimental, que gracias al descubrimiento de la estructura de la molécula del DNA le permite interpretar, explicar y hasta predecir los procesos del complejo sistema biológico con ayuda de la física, química, matemáticas, termodinámica, etc.

En biología, los conceptos, teorias, descripciones etc. se refieren a hechos concretos, a cuestiones realesyqueporobservación opor resultados de reacciones bioquímicas, cálculos matemáticos u otros artificios se deduce su validez, su veracidad. El alumno, en su propósito de aprender, debe realizar una abstracción de tales procesos, aunque generalmente lo que ocurre es que acumula una serie de informaciones (conocimientos) y que posteriormente se evalúa lo que sabe (su nivel de conocimientos), "según su capacidad de dar la respuesta correcta" (Moore p. 48).

\section{LOSCONTENIDOSENLAENSEÑANZA-APRENDIZA- JE DE LA BIOLOGIA}

La enseñanza-aprendizaje de la biología requiereal igual que las otras materias, un manejo adecuado de los contenidos curriculares para lograr los objetivos generales del sistema educativo. En cuanto se refiere a los contenidos, una de las incógnitas que surge es, ¿qué se debe enseñar?.Si se consideran los contenidos como aquellos conocimientos que permitan al alumno alcanzar una concepción integradora de su realidad, que lo faculte a desentrañar la madeja del azar y el determinismo que interconectan la estructura de los fenómenos biológicos ysu secuencia espacio-tiempo, reconociendo la condición trascendental dela vida (delos organismos vivos), entonces se logrará, no sólo hacer ciencia enseñando, sino que los alumnos adquieran un exacto conocimiento de la naturaleza, la sociedad y el pensamiento.

Para ello es necesario que se reactualice, en todos los niveles educacionales, la concepción, la estructura, la secuencia y la modernización de los contenidos curriculares y todos aquellos aspectos colaterales que le competen (por ejemplo, objetivos educacionales, actividades, evaluación, etc.). Es conveniente también, una adecuada dosificación de los contenidos, una óptima vulgarización de los conocimientos (con buen uso del lenguaje, sin alterar el significado y el significante) en los primeros años de estudios (primaria), practicar una enseñanza argumentativa, razonada enforma progresiva 
en los últimos años de primaria, con mayor énfasis en la secundaria y con mayor razón en la universidad. Es conveniente este esquema de enseñanza ya que “...Nadie estaría dispuesto a afirmar que la educación de los niños consiste exclusivamente en una materia deargumentación (aunque la argumentación puede entrar en ella y debería entrar en mayor medida de lo que es habitual), y casi todos coinciden ahora en lo que parece un resultado de la razón -el dominio del lenguaje, la existencia de un mundo perceptual ricamente articulado, la habilidad lógicase debe en parte a la enseñanza y en parte a un proceso de crecimiento que se desarrolla con fuerza de una ley natural. $Y$ donde los argumentos parecen tener efecto, esto se debe más a menudo a su repetición física que a su contenido semántico..." (Feyerabend p. 8)

En el sistema educativo, por otrolado, se puede afirmar que, todos los aspectos educacionales y los contenidos curriculares entre ellos, son en cierta medida, el resultado de la época en que se vive, y en última instancia, de las vivencias particulares de cada cual. Los conocimientos que se imparten (contenidos de los cursos) deben considerar tales cambios, tanto aquellos que van implícitos en su propia evolución, como los que derivan de las circunstancias que caracterizan el momento educativo. Al mencionar esto, se hace referencia a los cambios que ha sufridola biología, de la tradicional, clásica o descriptiva, a la biología moderna, marcada por el descubrimiento de la estructura del DNA. La primera, caracterizada por detallar, reseñar o representar la composición, la estructura, fenómenos y funcionamiento de los organismos. La segunda, por explicar y permitir interpretar de una forma científica, no solo los aspectos cualitativos y cuantitativos de los seres vivos actuales, sino los que faciliten realizar predicciones y hasta explicar el pasado con mucha certeza. La primera, muy difundida en los colegios a nivel primario, secundario y hasta en los centros de educación superior, entre ellas la universidad; la segunda, restringida a quienes hacen investigación,

\section{BIBLIOGRAFIA}

Afanasiev, V. 1981. Manual de Filosofía. Ed. Americana. Perú.

Bunge, Mario 1972. La ciencia: su método y su filosofía. Ediciones Siglo Veinte. Buenos Aires.

Capella, R. Jorge 1989. Educación un enfoque integral. Ed. Cultura y Desarrollo. Perú.

Círigliano, Gustavo 1972. Filosofía de la Educación. Ed. Humanitas. Argentina.

Doriga, Enrique 1988. Lecciones de Filosofía. Centro de Investigación de la Universidad del Pacífico. Lima.

Feyerabend, Paul 1992. Tratado contra el método. Edit. postgrado o algún tipo de especialización. El mundo actual requiere que esta biología moderna, sin dejar de lado la biología tradicional, sea llevada a los colegios y con mayor razón a las universidades; sin embargo se ha seguido trabajando con la concepción tradicional, lo cual se traduce en las respectivas currículas. Así, Afanasiev, al mencionar la esencia de la ciencia y el papel que desempeña en el desarrollo de la sociedad afirma: “...La particularidad más importante del desarrollo de la ciencia es la continuidad de los conocimientos científicos. Cadanuevageneración dehombresycadanueva sociedad no dejan a un lado las conquistas científicas del pasado, sino que las adoptan y las siguen desarrollando de acuerdo con las nuevas demandas prácticas...".

Ante esta propuesta, algunos docentes señalan que no se puede enseñar tantos conceptos, términos técnicos, nuevos enfoques de los fenómenos biológicos ya que se puede provocar rechazo a la materia por lo "complicado" de los procesos biológicos ysu metodología de estudio. Por lo general, en la universidad se prefiere enseñar de acuerdo a una concepción histórica de esta ciencia, con lo cual se pierde mucho de los nuevos descubrimientos de los últimos años y así se forman docentes que se caracterizan por su subordinación a la concepción histórica de la biologíay, por tanto, cualquier alteración de ese orden es inaceptable. Tal como lo enfatiza Magendzo: “...hoy es casi imposible imaginar la educación sin alguno o todos los fantasmas presentes o rondando con apetencia insaciable. Estos se combinan para formar redes que atrapan todo el quehacer de las escuelas. El fantasma del orden se reviste en las instituciones educativas de formas múltiples... En nombre del orden se permite trasgredir principios básicos del proceso educativo... El orden está presente en el currículum... se articula en la secuencia de contenidos y de objetivos. Hay progresión jerárquica, no se aceptan los saltos..." (Magendzo p. 93).

Tecnos. Madrid.

Magendzo, Abraham 1991. Superando la racionalidad instrumental. Ensayos en busca de un nuevo paradigma para la educación de los derechos humanos. Chile.

Makabe, Pedro 1989. ElCambio Epistemológico. Ed.San Marcos. Lima.

Moore, T.W.1987. Introducción a la filosofía de la Educación. Ed. Trillas. Primera edición. México.

Russel, Bertrand 1980. Los problemas de la Filosofía. Ed. Labor S.A. Barcelona. 